\title{
Do we need more than ultrasound endometrial thickness to predict malignancy?
}

\author{
Adly N. Al Fattah*, Tricia D. Anggraeni, Bella Aprilia, Muhammad Ikhsan
}

Department of Obstetrics and Gynecology, Dr. Cipto Mangunkusumo National General Hospital, Faculty of Medicine Universitas Indonesia, Jakarta, Indonesia

Received: 26 December 2017

Revised: 07 January 2018

Accepted: 24 January 2018

\section{*Correspondence:}

Dr. Adly N. Al Fattah,

E-mail: adlynanda@yahoo.com

Copyright: ( ) the author(s), publisher and licensee Medip Academy. This is an open-access article distributed under the terms of the Creative Commons Attribution Non-Commercial License, which permits unrestricted non-commercial use, distribution, and reproduction in any medium, provided the original work is properly cited.

\begin{abstract}
Endometrial thickness (ET) ultrasound measurement has high diagnostic performance for detection of endometrial cancer in symptomatic postmenopausal women. Identified clinical risk factors, Doppler or 3D ultrasound parameters to predict endometrial malignancy had been proposed in several studies. We compared the accuracy of ultrasound endometrial thickness with scoring system/index involving both of clinical and ultrasound parameters to predict endometrial malignancy. Eight eligible diagnostic studies were appraised to assess the accuracy of ultrasound ET and/or ultrasound-based index to predict malignancy. The incidence of endometrial malignancy confirmed by histopathology examination was ranging from 10.5 to $58 \%$ from 8 studies. Ultrasound-based index to predict endometrial malignancy had good accuracy (AUC 75\% - 98\%). The addition of endometrial volume/uterine corpus volume ratio (EV/UCV) and Doppler to clinical parameters had increased the prediction accuracy of the index. While ultrasound ET alone has also high sensitivity, respectively $90.6 \%$ and $96.9 \%$ using the cut-off $4 \mathrm{~mm}$ and $3 \mathrm{~mm}$ with low accuracy. Ultrasound-based index to predict endometrial malignancy had better accuracy compared to ultrasound ET alone. Combination of ultrasound including Doppler parameters and clinical parameters had increased the prediction accuracy of the endometrial malignancy prediction index.
\end{abstract}

Keywords: Clinical, Doppler, Endometrial cancer, Ultrasound

\section{INTRODUCTION}

Endometrial cancer is one of the most common gynecological malignancies. It develops in about 142,000 women worldwide, and lead to approximately 42,000 of mortality. ${ }^{1}$ Transvaginal ultrasound followed by endometrial biopsy is the most cost-effective diagnostic approach in the population with post-menopausal bleeding. ${ }^{2}$ We therefore consider TVU as the first step in any woman presenting with postmenopausal bleeding. ${ }^{3}$ Ultrasonography is a non-invasive method that could assess the morphologic structures of endometrium. ${ }^{4,5}$
Sonographically determined endometrial thickness measurement shows high diagnostic performance for detection of endometrial cancer in symptomatic postmenopausal women. ${ }^{6}$ In addition, there is no universally accepted sonomorphologic criteria to define benign or malignant structure on the endometrium. In order to make the prediction accuracy better, some studies created a scoring system involving clinical and ultrasound parameters. ${ }^{7,8} \mathrm{We}$ aim to appraise studies that assess the accuracy of endometrial malignancy prediction system or index which involving ultrasound as one of the predictors. 


\section{ACCURACY OF ULTRASOUND TO PREDICT ENDOMETRIAL MALIGNANCY}

Eight eligible studies were appraised to assess the accuracy of ultrasound and/or ultrasound index to predict malignancy. The incidence of endometrial malignancy confirmed by histopathology examination was ranging from 10.5 to $58 \%$ from 8 studies. The accuracy of ultrasound-based index to predict endometrial malignancy was ranging from $75 \%$ - 98\% from eight studies. Opolskiene, et al conducted a consecutive study of 729 post-menopausal bleeding, to evaluate the diagnostic performance of models predicting endometrial cancer. They stated that the accuracy was increased significantly when endometrial thickness and power Doppler assessment are added to clinical variables.

Clinical model including the variables age, use of warfarin and use of hormone replacement therapy had the largest area under the receiver-operating characteristics curve (AUC), with a value of 0.74 (95\% confidence interval (CI), 0.67-0.81). A model including age, use of warfarin and endometrial thickness had an AUC of 0.82 (95\% CI, 0.76-0.87), and one including age, use of hormone replacement therapy, endometrial thickness and vascularity index had an AUC of 0.91 (95\% CI, 0.87$0.95){ }^{9}$

Dueholm, et al concluded that simple Doppler score (which considered only presence of vascularity and not presence of single/double dominant vessel, multiple vessels, large vessels, color splash or densely packed vessels) had an AUC of 0.83 in the prediction of endometrial cancer. Prediction index including endometrial thickness, Doppler score and interrupted endomyometrial junction on unenhanced TVS predicted endometrial cancer with an AUC of 0.95 (95\% CI, $0.92-$ 0.99 ) and, with addition of irregular surface on GIS, the AUC was 0.97 (95\% CI, 0.94-0.99). ${ }^{10}$

In further study they compare the offline and real time evaluation during scanning to assess efficiency of twodimensional (2D) and three-dimensional (3D) TVU, power Doppler angiography (PDA) and gel infusion sonography (GIS) to detect endometrial malignancy. ${ }^{11}$ Diagnostic efficiency of 3D analysis may be improved by use of risk of endometrial cancer (REC)-scoring systems, without the need for calculation of vascular or endometrial volume. The REC consisted of: (1) body mass index $\geq 30 \quad$ ( +1 point), (2) total endometrial thickness $\geq 10 \mathrm{~mm}$ (+1 point), (3) total endometrial thickness $\geq 15 \mathrm{~mm} \quad(+1$ point $)$, (4) interrupted endomyometrial junction $(+1$ point) and (5) irregular surface at gel instillation sonography (GIS) (+1 point).

The first model included BMI, endometrial thickness, presence of an interrupted endomyometrial junction and Doppler score, had AUC of 0.879. Evaluation of 3D-GIS with BMI, an interrupted endomyometrial junction,
Doppler score and irregular endometrial surface at 3DGIS, had the highest diagnostic efficiency on multivariate regression, with an AUC of 0.908. Application of the REC-score system at 3D-PDA or 3D-GIS had comparable efficiency compared with their respective 2D models. $^{11}$

Burbos et al created a model to predict endometrial carcinoma in postmenopausal women called DEFAB (Diabetes, Endometrial thickness, Frequency of bleeding, Age, and BMI). In the DEFAB criteria, presence of diabetes in a patient scores 2; endometrial thickness $\geq 14 \mathrm{~mm}$ scores 1 , recurrent episodes of bleeding scores 4 ; age $\geq 64$ years scores 1 ; and $\mathrm{BMI} \geq 31 \mathrm{kgm}^{2}$ scores 1 . The value $\geq 3$ has a positive predictive value (PPV) of $7.78 \%$ and negative predictive value (NPV) of $98.2 \%$, whereas a score equal to or greater than 5 has a PPV of $11.9 \%$ and NPV of $97.8 \% .^{12}$

Seekin et al investigated the accuracy of endometrial thickness in predicting endometrial pathologies in both of symptomatic (group 1) and asymptomatic (group 2) postmenopausal women.

The best cut-off point for endometrial thickness in predicting endometrial carcinoma in group 1 was $8.2 \mathrm{~mm}$, which provided $75 \%$ sensitivity and $74 \%$ specificity; area under the AUC of $0.88 ; 95 \%$ CI, 0.76-1.00\%. In group 2, the AUC was 0.76 (95\% CI, 0.46-1.00; p 5 0.114). 6. In other study, Patel, et al stated that threshold of $4 \mathrm{~mm}$, the sensitivity is $90.6 \%$ and increases to $96.9 \%$ when decreasing the threshold to $3 \mathrm{~mm} .{ }^{13}$

Mansour, et al evaluated the role of endometrial/uterine corporeal volume ratio (EV/UCV) assessment in the prediction of endometrial cancer. EV/UCV of a cutoff value 0.017 was predictive of malignancy. Endometrial/uterine volume ratio was more sensitive than endometrial volume and endometrial thickness for prediction of endometrial cancer. ${ }^{7}$

Mihajovic, created the transvaginal ultrasound score for endometrial malignancy prediction consisted of: thickness of endometrium (up to five $\mathrm{mm}=0$, from five to eight $\mathrm{mm}=1$, >eight $\mathrm{mm}=2$ ), echogenicity of the endometrium compared to the myometrium: normal echogenicity $=0$, hyperechogenous $=1$, hypoechogenous $=2$, the border of the endometrium towards the myometrium - subendometrial hypoechogenous zone ( whole $=0$, intermittent $=1$ ), homogeneity of the texture of the endometrium (homogenous $=1$, inhomogeneous=2), presence of the colored signals in the endometrium (present $=2$, absent $=1$ ), index of resistance in newlyformed blood vessels in the endometrium $(>0.4=1$, $<0.40=2$ ), volume of the endometrium by an ultrasound check-up $(<13 \mathrm{ml}=1,>13 \mathrm{ml}=2)$. Score system showed that the value 8 had the best validity for the detection of endometrial malignity, with the sensitivity of 0.857 and specificity of $0.785 .^{4}$ 
Table 1: Eight eligible studies.

\begin{tabular}{|c|c|c|c|c|c|}
\hline Reference & $\begin{array}{l}\text { Eligible } \\
\text { for } \\
\text { analysis }\end{array}$ & Design & Required parameters & $\begin{array}{l}\text { Endometrial } \\
\text { malignancy } \\
\text { rate }\end{array}$ & $\begin{array}{l}\text { Result (accuracy for } \\
\text { endometrial malignancy) }\end{array}$ \\
\hline Opolskiene & 729 & $\begin{array}{l}\text { Cross- } \\
\text { sectional }\end{array}$ & $\begin{array}{l}\text { - Age, use of warfarin and endometrial thickness } \\
\text { Age, use of hormone replacement therapy, } \\
\text { endometrial thickness and vascularity index }\end{array}$ & $24 \%$ & $\begin{array}{l}\text { AUC } 0.82 \\
\text { Sens } 84 \% \text {, Spec } 66 \% \text {, LR+ } \\
2,49 \text {, LR } 0,24 \\
\text { AUC } 0,91 \\
\text { Sens } 90 \% \text {, Spec } 77 \% \text {, } \\
+ \text { LR } 3.14,- \text { LR } 0.13 .\end{array}$ \\
\hline Dueholm & 432 & $\begin{array}{l}\text { Cross- } \\
\text { sectional }\end{array}$ & $\begin{array}{l}\text { Presence of vascularity and not presence of } \\
\text { single/double dominant vessel, multiple vessels, } \\
\text { large vessels, color splash or densely packed } \\
\text { vessels } \\
\text { Endometrial thickness, Doppler score and } \\
\text { interrupted endomyometrial junction on } \\
\text { unenhanced TVS } \\
\text { Endometrial thickness, Doppler score and } \\
\text { interrupted endomyometrial junction on } \\
\text { unenhanced TVS with addition of irregular } \\
\text { surface on GIS }\end{array}$ & $41 \%$ & $\begin{array}{l}\text { AUC } 0.83 \\
\text { AUC } 0.95 \\
\text { AUC } 0.97\end{array}$ \\
\hline $\begin{array}{l}\text { Burbos et } \\
\text { al }\end{array}$ & 3047 & $\begin{array}{l}\text { Cross- } \\
\text { sectional }\end{array}$ & $\begin{array}{ll}\text { - } & \text { Norwich DEFAB prediction: } \\
\text { - } & \text { Diabetes } \\
\text { - } & \text { Endometrial thickness (ET) } \\
\text { - } & \text { Age } \\
\text { - } & \text { BMI }\end{array}$ & $58 \%$ & $\begin{array}{l}\text { AUC } 0.77 \\
\text { ET Cut-off } \geq 3 \mathrm{~mm} \\
\text { PPV } 7.78 \% \\
\text { NPV: } 98.2 \% \\
\text { ET Cutoff } \geq 5 \mathrm{~mm} \\
\text { PPV } 11.9 \% \\
\text { NPV: } 97.8 \%\end{array}$ \\
\hline Dueholm & 169 & $\begin{array}{l}\text { Prospective } \\
\text { cohort }\end{array}$ & $\begin{array}{l}\text { BMI, interrupted endomyometrial junction, } \\
\text { Doppler score, irregular endometrial surface at } \\
\text { 3D-GIS (Model 4) } \\
\text { REC score 3D-PDA (BMI } \geq 30, \mathrm{ET} \geq 10 \mathrm{~mm}, \\
\text { ET } \geq 15 \mathrm{~mm} \text {, interrupted endomyometrial } \\
\text { junction, Doppler score) } \\
\text { REC score 3D-GIS (BMI } \geq 30, \mathrm{ET} \geq 10 \mathrm{~mm}, \\
\text { ET } \geq 15 \mathrm{~mm} \text {, interrupted endomyometrial junction, } \\
\text { Doppler score, irregular surface at 3D-GIS) }\end{array}$ & $40.8 \%$ & $\begin{array}{l}\text { AUC: } 0.908, \text { Sens } 85.3 \% \\
\text { Spec } 89.3 \% \\
\text { AUC: } 0.88, \text { Sens } 86.9 \% \text {, } \\
\text { Spec } 81 \% \\
\text { AUC: } 0.894 \text {, Sens: } 85.3 \% \\
\text { Spec: } 86.9 \%\end{array}$ \\
\hline Mihajlovic & 100 & $\begin{array}{l}\text { Cross- } \\
\text { sectional }\end{array}$ & $\begin{array}{l}\text { Thickness of endometrium } \\
\text { Echogenicity of the endometrium compared to } \\
\text { the myometrium } \\
\text { The border of the endometrium towards the } \\
\text { myometrium - subendometrial hypoechogenous } \\
\text { zone } \\
\text { Presence of the coloured signals in the } \\
\text { endometrium } \\
\text { Index of resistance in newly-formed blood } \\
\text { vessels of the endometrium } \\
\text { Volume of the endometrium by an ultrasound } \\
\text { check-up }\end{array}$ & $21 \%$ & $\begin{array}{l}\text { Cutoff: } 8 \\
\text { Sens } 85.7 \% \text {, Spec } 78,5 \%\end{array}$ \\
\hline Mansour & 160 & $\begin{array}{l}\text { Cross- } \\
\text { sectional }\end{array}$ & $\begin{array}{l}\text { - An endometrial/ uterine volume (EV/UCV) ratio } \\
\text { - } \quad \text { Endometrial thickness } \\
\text { Endometrial volume in cc }\end{array}$ & $16.87 \%$ & $\begin{array}{l}\text { Cutoff: } 0.017 \text {, Accuracy: } \\
\text { 98\%, Sens: } 99 \% \text {, Spec: } 98 \% \text {, } \\
\text { PPV: } 98 \% \text {, NPV:99\% } \\
\text { Cutoff: } 5 \text { mm, Accuracy: } \\
\text { 75\%, Sens: } 68 \% \text {, Spce: } 82 \% \text {, } \\
\text { PPV: 77\%, NPV:74\% } \\
\text { Cutoff: } 1.4 \text { cc, Accuracy: } \\
\text { 86\%, Sens: } 81 \% \text {, Spec:90\%, } \\
\text { PPV: } 88 \%, \text { NPV:84\% }\end{array}$ \\
\hline Seekin & 602 & $\begin{array}{l}\text { Cross- } \\
\text { sectional }\end{array}$ & Endometrial thickness & $\begin{array}{l}\text { Symptomatic } \\
\text { group: } 2,9 \% \\
\text { Asymptomatic } \\
\text { group: } 0,9 \%\end{array}$ & $\begin{array}{l}\text { Cutoff } \geq 8.2 \mathrm{~mm} \\
\text { Sens } 75 \%, \text { Spec } 74 \%, \\
\text { AUC: } 0.88 \\
\text { Cutoff } \geq 5 \mathrm{~mm} \\
\text { AUC: } 0.76\end{array}$ \\
\hline Patel et al & 304 & $\begin{array}{l}\text { Cross- } \\
\text { sectional }\end{array}$ & Endometrial thickness & $10.5 \%$ & $\begin{array}{l}\text { Cutoff } 4 \mathrm{~mm} \text {, Sens: } 90.6 \% \\
\text { Cut off } 3 \mathrm{~mm} \text {, Sens: } 96.9 \%\end{array}$ \\
\hline
\end{tabular}


Table 2: Appraisal table.

\begin{tabular}{|c|c|c|c|c|c|c|c|c|c|c|c|}
\hline \multirow{2}{*}{ Study } & \multirow{2}{*}{ Population } & \multicolumn{3}{|c|}{ Validity } & \multicolumn{5}{|l|}{ Result } & \multirow{2}{*}{$\begin{array}{l}\text { Applicability } \\
9\end{array}$} & \multirow{2}{*}{$\begin{array}{l}\text { Total } \\
\text { Score }\end{array}$} \\
\hline & & 1 & 2 & 3 & $4(\mathrm{Sn})$ & $5(\mathbf{S p})$ & 6 (PPV) & 7 (NPV) & 8 AUC & & \\
\hline \multicolumn{12}{|l|}{ Opolskiene } \\
\hline Clinical parameters, ET & 729 & & & & $84 \%$ & $66 \%$ & - & - & 0.82 & \multirow[b]{2}{*}{+} & $7 / 9$ \\
\hline $\begin{array}{l}\text { Clinical parameters, ET } \\
\text { and vascularity index }\end{array}$ & & + & + & + & $90 \%$ & $77 \%$ & - & - & 0.91 & & $7 / 9$ \\
\hline \multicolumn{12}{|l|}{ Dueholm } \\
\hline Presence of vascualrity & 432 & \multirow{3}{*}{+} & \multirow{3}{*}{+} & \multirow{3}{*}{+} & - & - & - & - & 0.83 & \multirow[b]{3}{*}{+} & $4 / 9$ \\
\hline $\begin{array}{l}\text { ET, Doppler, TVS } \\
\text { parameter }\end{array}$ & & & & & & & & & 0.95 & & $4 / 9$ \\
\hline $\begin{array}{l}\text { ET, Doppler, TVS } \\
\text { parameter + irregular } \\
\text { surface on GIS }\end{array}$ & & & & & & & & & 0.97 & & $4 / 9$ \\
\hline \multicolumn{12}{|l|}{ Burbos, et al } \\
\hline Cutoff $\geq 3 \mathrm{~mm}$ & \multirow{2}{*}{3047} & \multirow{2}{*}{+} & \multirow{2}{*}{+} & \multirow{2}{*}{+} & - & - & $7.78 \%$ & $98.25 \%$ & \multirow{2}{*}{0.76} & \multirow{2}{*}{+} & $4 / 9$ \\
\hline Cutoff $\geq 5 \mathrm{~mm}$ & & & & & - & - & $11.9 \%$ & $97.8 \%$ & & & $4 / 9$ \\
\hline \multicolumn{12}{|l|}{ Seekin } \\
\hline Cutoff $\geq 8.2 \mathrm{~mm}$ & 602 & \multirow{2}{*}{+} & \multirow{2}{*}{+} & \multirow{2}{*}{+} & $75 \%$ & $74 \%$ & - & - & 0.88 & \multirow{2}{*}{+} & $4 / 9$ \\
\hline Cutoff $\geq 5 \mathrm{~mm}$ & & & & & & & & & 0.76 & & $4 / 9$ \\
\hline \multicolumn{12}{|l|}{ Dueholm } \\
\hline Moedl 4 & 169 & \multirow{3}{*}{+} & \multirow{3}{*}{+} & \multirow{3}{*}{+} & $85.3 \%$ & $89.3 \%$ & - & - & 0.90 & \multirow{3}{*}{-} & $6 / 9$ \\
\hline REC score 3D-PDA & & & & & $86.9 \%$ & $81 \%$ & - & - & 0.88 & & $6 / 9$ \\
\hline REC score 3D-GIS & & & & & $85.3 \%$ & $86.9 \%$ & - & - & 0.89 & & $6 / 9$ \\
\hline Mansour & & & & & & & & & & & \\
\hline EV/UCV & 160 & & & & $99 \%$ & $98 \%$ & $98 \%$ & $99 \%$ & 0.98 & & $9 / 9$ \\
\hline Endometrial thickness & & & & & $68 \%$ & $82 \%$ & $77 \%$ & $74 \%$ & 0.75 & + & $5 / 9$ \\
\hline Endometrial volume in cc & & + & + & + & $81 \%$ & $90 \%$ & $88 \%$ & $84 \%$ & 0.86 & & $9 / 9$ \\
\hline Mihajovic & 100 & + & + & + & $85.7 \%$ & $78.5 \%$ & - & - & - & + & $5 / 9$ \\
\hline Patel et al & & & & & & & & & & & \\
\hline Cutoff $4 \mathrm{~mm}$ & 304 & & & & $90.6 \%$ & - & - & - & - & & $5 / 9$ \\
\hline Cutoff $3 \mathrm{~mm}$ & & + & + & + & $96.9 \%$ & - & - & - & - & + & $5 / 9$ \\
\hline
\end{tabular}

\section{DISCUSSION}

In present study, the incidence of endometrial malignancy was varied among studies. It could possibly explain by the variation of the population. In some studies, they included women with a complaint of postmenopausal bleeding who has endometrial thickness $\geq 4.5 \mathrm{~mm}^{9}$, while other studies included subjects without considering the ET. ${ }^{12,14}$ We found the incidence of endometrial malignancy from 5 to $58 \%$. It was similar with the finding from The Gynecologic Oncology Group (GOG) that found $42.6 \%$ of endometrial malignancy, 123 of 289 specimens. ${ }^{14}$

Sorosky in their review stated that the positive predictive value and negative predictive value of an office biopsy are greater than $90 \% .{ }^{14}$ TVS screening for endometrial cancer has good sensitivity in postmenopausal women. ${ }^{15}$ In addition, in certain conditions in which the cervical canal could not be accessed by curettage, the role of ultrasound will be useful to predict malignancy.

Monsour had the highest appraisal score, because they show all the diagnostic parameters of their result.
Transvaginal 3D render mode ultrasound was used to assess the volume of the uterus in the coronal plane using manual lining technique. Volumes were manually calculated in the coronal plane with $30^{\circ}$ rotation steps. They found that EV/UCV had the best in prediction of malignancy compared to endometrial thickness and endometrial volume; AUC (area under the curve) for endometrial thickness, volume and EV/UCV was respectively 75,92 and $100 \%$. However, further studies should be conducted with a larger number of subjects to support these findings. ${ }^{7}$ The interobserver and intraobserver reproducibility of 3D ultrasound for assessment of endometrial volume measurements in patients with postmenopausal bleeding was well proved, showing better reproducibility than 2D measurement of endometrial thickness. ${ }^{7}$

Using ultrasound parameter, the accuracy of prediction index was higher compared to the non-ultrasound based index. In our study, the accuracy of prediction index involving ultrasound parameters was ranging from 0,75 to 0.98 . It was higher compared to the clinical-based prediction index. Burbos, et al created a clinical predictive model called FAD 31 ( $\mathrm{F}$ for the frequency of 
bleeding episodes, A for the age of the patient, D for diabetes, and number 31 represents the BMI cut-off value). The AUC was 0.73. Among 14 recognized indexes in our appraisal study, only 3 indexes had the AUC below $0.8 .^{8}$

\section{CONCLUSION}

Ultrasound-based index to predict endometrial malignancy had good accuracy. Addition of endometrial thickness and power Doppler to clinical parameters had increased the prediction accuracy. EV/UCV had the best in prediction of malignancy compared to endometrial thickness and endometrial volume. Further larger study should be conducted to assess the effectivity and eligibility of several ultrasound parameters.

Funding: No funding sources

Conflict of interest: None declared

Ethical approval: Not required

\section{REFERENCES}

1. Amant F, Moerman P, Neven P, Timmerman D, Van Limbergen E, Vergote I. Endometrial cancer. Lancet. 2005 Aug;366(9484):491-505.

2. Breijer MC, Van Doorn HC, Clark TJ, Khan KS, Timmermans A, Ben J Mol, et al. Diagnostic strategies for endometrial cancer in women with postmenopausal bleeding: cost-effectiveness of individualized strategies. Eur J Obstet Gynecol. Elsevier Ireland Ltd; 2012 Jul;163(1):91-6.

3. Dijkhuizen FPHLJ, Mol BWJ, Br lmann HAM, Heintz APM. Cost-effectiveness of the use of transvaginal sonography in the evaluation of postmenopausal bleeding. Maturitas. 2003 Aug;45(4):275-82.

4. Mihajlovic S, Vasiljevic M, Jurisic A, KisicTepavcevic, Dimitrijevic D, Nejkovic L. Predictive value of transvaginal ultrasound score for detection of endometrial malignancy. Clin Experiment Obstet Gynecol. 2016 Oct 30:1-6.

5. Clark TJ. Outpatient hysteroscopy and ultrasonography in the management of endometrial disease. Curr Opin Obstet Gynecol. 2004 Aug;16(4):305-11.

6. Seckin B, Cicek MN, Dikmen AU, Bostanc EI, Muftuoglu KH. Diagnostic value of sonography for detecting endometrial pathologies in postmenopausal women with and without bleeding. J Clin Ultrasound. 2016 Feb 9;44(6):339.
7. Mansour GM, El-Shalakany A. Endometrial/uterine corporeal volume ratio (EV/UCV) as predictor of malignancy in women with postmenopausal bleeding. Arch Gynecol Obstet. 2011 Aug 24;285(3):831-8.

8. Burbos N, Musonda P, Duncan TJ, Crocker SG, Morris EP, Nieto JJ. Estimating the Risk of Endometrial Cancer in Symptomatic Postmenopausal Women. Int J Gynecol Cancer. 2011 Apr;21(3):5006.

9. Opolskiene G, Sladkevicius P, Valentin L. Prediction of endometrial malignancy in women with postmenopausal bleeding and sonographic endometrial thickness $>4.5 \mathrm{~mm}$. Ultrasound Obstet Gynecol. 2011 Jan 19;37(2):232-40.

10. Dueholm M, M ller C, Rydbjerg S, Hansen ES, rtoft G. An ultrasound algorithm for identification of endometrial cancer. Ultrasound Obstet Gynecol. 2014 May 2;43(5):557-68.

11. Dueholm M, Christensen JW, Rydbjerg S, Hansen ES, rtoft G. Two- and three-dimensional transvaginal ultrasound with power Doppler angiography and gel infusion sonography for diagnosis of endometrial malignancy. Ultrasound Obstet Gynecol. 2015 Jun 2;45(6):734-43.

12. Burbos N, Musonda P, Giarenis I, Shiner AM, Giamougiannis P, Morris EP, et al. Predicting the risk of endometrial cancer in postmenopausal women presenting with vaginal bleeding: the Norwich DEFAB risk assessment tool. Br J Cancer. 2010 Mar 30;102(8):1201-6.

13. Patel V, Wilkinson EJ, Chamala S, Lu X, Castagno J, Rush D. Endometrial Thickness as Measured by Transvaginal Ultrasound and the Corresponding Histopathologic Diagnosis in Women With Postmenopausal Bleeding. Int J Gynecologic Pathol. $2017 \mathrm{Jul} ; 36(4): 348-55$.

14. Sorosky JI. Endometrial Cancer. Obstet Gynecol. 2008 Jan;111:1-12.

15. Jacobs I, Burnell M, Manchanda R, Singh N, Sharma A, et al. Sensitivity of transvaginal ultrasound screening for endometrial cancer in postmenopausal women: a case-control study within the UKCTOCS cohort. Lancet Oncol. 2010 Dec 18;12(1):38-48.

Cite this article as: Al Fattah AN, Anggraeni TD, Aprilia B, Ikhsan M. Do we need more than ultrasound endometrial thickness to predict malignancy?. Int J Reprod Contracept Obstet Gynecol 2018;7:766-70. 